'It spreads like a creeping disease': Experiences of victims of disability hate crimes in austerity Britain

Disability \& Society (accepted 23 May 2019)

Jane C Healy

Department of Social Science \& Social Work, Bournemouth University, Bournemouth, UK.

Correspondence details: jhealy@bournemouth.ac.uk

Orchid: 0000-0002-3646-0565

Acknowledgements: The research was funded by a $1+3 \mathrm{PhD}$ scholarship from Middlesex University's Institute of Social and Health Research. 


\title{
Title:
}

\section{'It spreads like a creeping disease': Experiences of victims of disability hate crimes in austerity Britain}

\begin{abstract}
:
This paper examines disabled people's experiences of hate crime during a period of austerity and welfare reform. Narrative interviews were conducted with 12 victims of disability hate crimes in the UK who experienced a spectrum of targeted, disablist violence and harassment, from name-calling and verbal abuse to physical and sexual violence, harassment and damage to property. Participants expressed frustration and disappointment with inadequate, offensive and inappropriate responses from the criminal justice system. This resulted in a lack of confidence in reporting their experiences to police in future. Evidence from participant stories encapsulates the diversity of disability hate crime perpetrators, from neighbour to stranger, resulting in a lack of safe space in which disabled people can live and work. Examination of these findings illustrates the impact of contemporary structural discourses of conditionality and stigma upon disabled people, including acceptance of and resilience to hate crimes.
\end{abstract}

Keywords:

Disability hate crime: disablism; victims; narrative interviews; police; safe spaces

Points of Interest:

- Disabled people experience hate crime a lot of the time; this includes verbal abuse, harassment, accusations of fraud, threatening behaviour, sexual abuse, violence and online abuse.

- This means there are few 'safe spaces' where disabled people will not be targeted.

- Some of the people who commit hate crimes against them are strangers, others are people they know. 
- Disabled people are often disappointed and frustrated by how the police respond to them when they report these crimes.

\section{Main Text:}

\section{Introduction}

Disabled people are at greater risk of being victims of violent crimes and theft than non-disabled people (Emerson and Roulstone 2014, ODI 2011, Walker 2009, Sin et al. 2009a, Greenhalgh and Gore 2009, Vincent et al. 2009, GLAD 2004, NACRO 2002). Disabled people also report that their initial experiences of hate crime is 'low level' or hate incidents, often in the form of harassment or intimidation (Piggott 2011, Sin et al. 2009a, Gillen 2007, Wood and Edwards 2005, Disability Rights Commission 2004, Berzins, Petch and Atkinson 2003, NSF 2001). However, incidents often escalate in severity and frequency, with victims experiencing verbal and physical violence, abuse and harassment over several months and years (Richardson et al. 2016, Williams and Tregidga 2014, Chakraborti, Garland and Hardy 2014b, Pettitt et al. 2013, Sherry 2013a, 2010, EHRC 2011, CPS 2010b, Vincent et al. 2009, Sin et al. 2009a, Action for Blind People 2008, NISRA 2007, ACPO 2005, Mason 2005, DRC 2004). Furthermore, evidence suggests that disability hate crime victimisation involves higher levels of threatening and intimidating behaviour and abusive language when compared to other hate strands (Macdonald, Donovan and Clayton 2017). Although they may be an everyday or minor manifestation of prejudice or discrimination, these incidents can result in significant harm if they are not reported or resolved (Mason 2005, GLAD 2004, Bowling 1998). Garthwaite $(2015,2014)$ proposes that these recent increases in disability hate crime are directly related to government policy changes to disability benefits, as a result of austerity measures following the global financial crisis. 
This article presents evidence from disabled people about their experiences of disability hate crimes. Interview participants recount a range of victimisation, from verbal abuse to sexual and physical violence. Findings are divided by three common themes; ongoing neighbourhood disputes; stranger-perpetrators; and the lack of a 'safe space' for disabled people resulting from a combination of these experiences. Reports to the police are also examined. These findings build upon previous studies, enhancing the validity and significance of this research (Sin, 2016), and contribute to a growing evidence base on experiences of and police response to disability hate crimes.

\section{What is disability hate crime?}

Although the differential and discriminatory treatment of disabled people has occurred throughout history (Hollomotz 2013, Sherry 2010, Petersilia 2001, Barton 1996, Sobsey 1994), acts of prejudice, hostility and hatred were not conceptualised under the 'hate crime' label until the latter part of the $20^{\text {th }}$ Century. The legal concept of hate crime emerged in the USA during the 1980s on the back of growing social and civil rights movements and identity politics (Levin 2013, Perry 2003, Jenness and Broad 1997) but it was not until the turn of the millennium that hate crime garnered serious interest amongst academics in the UK (Garland 2011, Hall 2013, 2005, Perry 2003). The catalyst for this was the murder of Stephen Lawrence in London in 1993 and the subsequent public inquiry in 1999 and publication of the Macpherson Report (Hall 2013, Macpherson 1999). Although the Inquiry focused on race and racism, it drew attention to other targets of hate-motivated offending, laying the groundwork for the legal recognition of hate 'strands'. The introduction of disability as a protected 'strand' of hate crime emerged following the review of the Race for Justice programme in the early part of this century (Giannasi 2015). Consequently, there are five legally protected 
characteristics, or 'strands' of hate crime in the UK: race/ethnic origin, religion/faith, sexual orientation, disability and gender identity (trans-gender).

Although the word 'hate' was intended to suggest a level of seriousness that should be addressed with some urgency (Mason-Bish 2013) it is generally accepted that much of hate crime is not about hate but about hostility or prejudice, or specifically, criminal behaviour motivated by hostility or prejudice, of which hatred may be one small part (Hall 2013, 2005). Hall describes 'hate crime' as an act which involves the targeting and victimising of a minority group, or member of a minority group, where prejudice or hatred towards that group was the motive or intent (2013, see also Jacobs and Potter 1998). In essence, this means that a perpetrator (or group of perpetrators) targets a disabled person or group because of their prejudice, hostility, bias or hatred. Consequently, current government guidance does not include the term 'hate' and states that a disability hate crime is:

"Any criminal offence which is perceived, by the victim or any other person, to be motivated by a hostility or prejudice based on a person's disability or perceived disability" (College of Policing 2014b, 4, italics added).

The Guidance also establishes protocols for disability-related incidents in that police forces are also required to monitor those incidents that are not criminal. When responding to a reported hate crime, if police determine that no recordable (or identifiable) criminal offence has occurred, the act should still be recorded as a noncrime hate incident. A hate incident may not constitute a criminal offence, but a pattern of incidents could indicate a potential social problem or be a precursor to further criminal behaviour (College of Policing 2014b). 
Although this guidance provides a definition for disability hate crime there is no specific disability hate crime 'law'. Section 146 of the Criminal Justice Act 2003 relates to disability hate crimes; the Act states that where a perpetrator is convicted of an offence, a court can enhance or increase that sentence to the maximum available if there is evidence of motivation of hostility or prejudice based on a person's disability (or perceived disability). This is referred to as an 'uplift' and it falls far short of the available legislation for racial and religious hatred, which have specific aggravated charges available to them. Thus, although according to the definition above, it is perception rather than motivation that is important in recognising hate crimes, the challenge for the courts is attempting to prove that such motivation exists. Prosecuting hate crimes requires evidence of hostility, something which is not always obvious or explicit.

This distinction has implications for understanding and responding to hate crimes, as many victims are unsure what exactly 'hate crime' is (Chakraborti, Garland and Hardy 2014a). Likewise, this research also found that participants rarely distinguished between crimes and incidents unless they were or had been criminal justice personnel. Additionally, the definition is deliberately broad in that a hate crime can be identified by the victim 'or any other person', with the hope that this would have a positive impact on recording of hate crime. However, this over-inclusiveness can also have a correspondingly negative impact. Unsustainable public expectations can result in frustration and/or disappointment for individuals and communities who perceive themselves to be victims of hate crime but where evidence of such motivation is lacking (Mason, McCulloch and Maher 2015). Not only can this create unrealistic expectations, it can further undermine the efficacy of hate crime policing strategy. Victims may become unwilling to report their experiences if they expect nothing will be done about 
them. Additionally, Walters, Wiedlitzka and Owusu-Bempah (2017), in interviews with CPS prosecutors, judges and magistrates, report how difficult it is for disability hate crime cases in particular to be prosecuted without some form of verbal abuse, often because of conflicting interpretations of what is meant by evidence of hostility. As a result, those who believe they have been victims of hate crime can feel let down at multiple stages by the response they receive from the criminal justice sector.

\section{Disablism or disability hate crime?}

The confusion surrounding how disability hate crime is defined and recognised is further complicated by the utility of the term 'disablism' by many academics and practitioners. Disablism is preferred by those who argue that it emphasises the structural aspects of prejudicial motivation in the same way that terms such as 'racist' and 'sexist' do (Sin 2015, Mason-Bish 2013, DWP 2012). Disablism is defined as "discriminatory, oppressive or abusive behaviour arising from the belief that disabled people are inferior to others" (Quarmby 2008, 8). Disability hate crimes are an extreme articulation of the prejudice, discrimination and marginalisation that disabled people thus face daily and are ultimately a manifestation of disablism (Richardson et al. 2016) or disablism in action. However, participants in this study used the phrase 'disability hate crime' rather than 'disablism' and as such the former is used throughout this paper.

\section{Impact of disability hate crime}

Despite the contentious nature of the Hate Crime label itself, it is recognised that ongoing patterns of violence and harassment can impact upon victims and broader society, that they are divisive and result in deterioration of relationships and reinforcement of barriers between groups (Perry 2015). Hate crimes have a significant 
impact on disabled victims and their engagement with society, leading to disabled people reporting significant psychological and physical impact following hate crime victimisation (Williams and Tregidga 2014, Sin et al. 2009b, Shapland and Hall 2007). There are repercussions of increasing hate crime victimisation for disabled people, as they restrict their own movements, withdraw and/or retaliate in response (Perry 2015). The effects of harassment, abuse or violence experienced by victims can include hospitalisation and in some cases attempted suicide or suicidal ideation (Chakraborti, Garland and Hardy 2014b, Pettitt et al. 2013, WHO 2011, Sin et al. 2009, NSF 2001). Impact can be even more pernicious in cases where there is a relationship between perpetrators and victims (Landman 2014, Thomas 2013, 2011, Petersilia 2001). Additionally, as some disabled people are reliant upon others to provide care for them, this can prevent them from resisting abuse from those in a caring position. Consequently, perpetrators may learn that they can victimise without fear of consequences. Some disabled people report being encouraged by carers, family members and society to ignore and accept negative behaviour towards them ( $\operatorname{Sin} 2013$ ). For example, disabled people with learning difficulties can fail to recognise their experiences of victimisation, exploitation and abuse, leaving them open to risk (Richardson et al. 2016). This conditioning results in an acceptance for disabled people that they have to live with certain forms of victimisation. A 'normalisation' of hate crime leads to victims feeling there is nothing that can be done (Richardson et al. 2016, Chakraborti 2015, Vincent et al. 2009, Blee 2007). This is notably so in areas of poverty and socio-economic restrictions, which are particularly associated with disability hate crimes (Emerson and Roulstone 2014, Brownridge 2006, Petersilia 2001). Vincent et al. $(2009,55)$ note how the impact on people's experiences is "especially acute for those who are often in the poorer groups in society and have to bear the financial impact of 
the loss and/or repairs to equipment". This then impacts upon disabled people's confidence and quality of life and presents an obstacle to reporting (Richardson et al. 2016).

The impact on disabled people and disabled communities is thus manifold; resulting in deteriorating physical and mental health, withdrawal from society and a normalisation and acceptance of violence and abuse. It is particularly prevalent for those living within lower socio-economic status and can result in victims losing both their social network and their homes as a consequence (Thiara and Hague 2013, DRC 2004, Perry 2004). As such, research in this area is warranted and relevant to all of society.

\section{Government Policy: Disabled Victims or Villains?}

Recent governments have made various positive and proactive policy statements and initiatives addressing hate crime and disabled people (e.g. Home Office 2016, HM Government 2012, HM Government 2009). For example, in 2005, the (then) Prime Minister's Strategy Unit (6) published a vision for disabled people in Britain where they "should have full opportunities and choices to improve their quality of life and will be respected and included as equal members of society". As inclusive as this sounds, narratives around disabled people have evolved and subsequent policy changes in relation to social welfare recipients have depicted disabled people as dependent, no longer in need of benefits and a group who need to be incentivised to work (Void 2013, Piggott 2011, Lawrence 2011).

Disabled people were front and centre of plans to reform welfare as a consequence of austerity measures put in place by the UK Government following the global financial crisis of 2007-08. As part of a commitment to reduce the overall national deficit following the UK's recession, 1.03 million existing claimants of out-of- 
work disability benefits, or incapacity benefit (IB), had their eligibility reassessed between 2010 and 2013, accounting for approximately $80 \%$ of the total IB existing claimants (Barr et al. 2016). The reassessment was in the form of the newly introduced Work Capability Assessment (WCA), where disabled claimants were either found fit for work, and moved off disability benefits, or transferred to a new disability benefit scheme called the Employment Support Allowance (ESA). In addition, the Disability Living Allowance, awarded to disabled people to help with extra costs associated with their disabilities and impairments, was being replaced by a Personal Independence Payment (PIP) in a bid to cut overall Department for Work and Pension (DWP) spending by $20 \%$. Disabled people were arguably already struggling financially before this succession of cuts was introduced; $84 \%$ of UK households that included at least one person with an impairment were reported to have difficulty managing their finances because of limited incomes (ODI 2011); and a higher proportion of families with a disabled member live in poverty than those with no disabled family members (ODI 2014). Thus, cuts were being instigated for those already stretched financially. Concerns were raised that the WCA process was also having an adverse effect on disabled people. The assessment and appeals process are both reported to be stressful and were resulting in additional financial penalties for those already on a low income if they are found to be fit for work, and an increase in self-reported mental health problems and suicides across England (Barr et al. 2016).

Quarmby (2013) reports that at the time of this benefit "crackdown" disabled people were presented as either villains or victims within popular news media. Language portrayed them as dependent, workshy and unwilling (Ralph, Capewell and Bonnett 2016, Garthwaite 2011). In much the same way as asylum seekers have been constructed as 'bogus' or 'genuine' (Ahmed 2001), disabled people were constructed as 
'deserving' or 'undeserving' benefit recipients, leading to increased social stigmatisation and suspicion (Garthwaite 2014) and labelling as 'fraudulent' or 'bogus'. Despite an increase in media coverage of disability hate crimes generally, the language used by news media to describe disabled people supported this narrative by focusing upon the extent of 'fraudulent' benefit claimants (Briant, Watson and Philo 2011, 2013, Garthwaite 2014, 2011). For example, BBC News (2011) incorrectly reported that $75 \%$ of benefit claimants who had been reassessed were either found fit to work or dropped their claims. Other British media attempts to disparage and shame disabled claimants added to this image of benefit cheat (Piggott 2011, Riley-Smith 2012, Richardson et al. 2016, Scope 2011). Where previously disability had been recognised as a legitimate social category and disabled people would have been seen as unable to work (Oliver 1990), increasingly this image has reversed and a narrative emerged of disabled people as being unwilling rather than unable.

Disabled people found themselves being blamed for austerity measures, being accused of fraud and being labelled scroungers. The UN Committee on the Rights of Persons with Disabilities reported that inciting criticism towards disabled people in this way had fuelled an increase in disability hate crimes (2016, see also Marsh 2011, Piggott 2011 and Quarmby 2015). Marsh (2011) places the blame for this scapegoating of disabled people directly at the Government's door, arguing that their 'tough line' policy that attempted to reduce the numbers claiming benefits has led directly to the media and public response. This narrative of 'fraudulent disabled people' underlies the social context within which this research was undertaken. 


\section{Methodology: Weaving Stories}

This paper presents partial findings of a $\mathrm{PhD}$ thesis investigating experiences of disability hate crime which utilised both constructivist and participatory approaches to research design. A qualitative methodological approach to hate crime enabled greater illumination of the emotional and psychological impact of hate crime (Iganski and Sweiry 2016) and the research framework drew upon elements of participatory research design in that participants were engaged 'with' rather than 'upon'. The focus was one of inclusive research that aimed to address issues that mattered to disabled participants (Nind 2017). A 'recursive' dialogue was established with participants, in order to discover and realise their practical, social and cultural needs (Cook and Inglis 2012) and the research proceeded collaboratively, in that participants contributed to the research process. Not only is participatory research with marginalised communities of utmost import, so is the way in which it is conducted, with particular focus upon whether disabled participants are being empowered or further alienated (Nind 2017, Aldridge 2014, Dupont 2008). As such, fundamental issues of empowerment and reciprocity with the research participants were built in through reflexivity and ongoing engagement with participants. Ethical approval was received from the Middlesex University Social Science Ethics Committee.

Narrative interviews were conducted with 12 disabled participants who were victims of disability hate crime. Nine were identified and approached through their completion of an e-survey that formed another phase within the thesis. A further two were interviewed through recommendations from a contact at a learning disability support group; and one was a key informant who was participating in another phase of the research and was also a victim of disability hate crime. The interviews explored personal experiences of crime, harassment and abuse, and the impact of these events on 
the participants in depth. They probed into what happened when participants reported hate incidents, and whether this resulted in a conviction and/or the application or 'uplift' from Section 146 of the Criminal Justice Act 2003. Although care workers were either not required or not present at the interviews, a support worker was in the room with two disabled participants with learning difficulties.

Narrative analysis is a popular method of interpreting, authentically, the voices and experiences of victims (van Dijk 2009) and interprets interviews as stories, or narratives, through which participants see their world (Esin 2011). This approach was suitable to both the constructionist and participatory paradigms of the research; that the participants are active narrators who 'weave' stories. In addition, narrative interviews are best suited to small to medium-sized numbers of research participants. The research priority was to achieve rich, detailed narratives rather than specify targeted quotas from the outset. The number of participants, therefore, was of less concern than the quality of the data (Esin 2011).

Research participants had a variety of disabilities, impairments and conditions. It is not uncommon for research studies to focus on a specific type of disability, condition or impairment, with a particular over-reliance on those with learning disabilities or mental health conditions (for example, Sin et al. 2009a, 2009b). By limiting research to specific groups with specific experiences, comparisons with other studies become more difficult (Sin et al. 2009b). There is also the risk of assuming certain forms of hate crimes apply only to specific types of disability or impairment, which is misleading as many disabled people have multiple forms of impairments and conditions. Defining disadvantage by one particular type of group can lead to exclusion for members of multiple-subordinated groups (Cole 2009) or assumptions as to the replicability of certain experiences to certain groups of disabled people. Notwithstanding, disabled 
people's experiences can vary considerably depending upon the nature of their impairment (Chakraborti and Garland 2009, Sin et al. 2009a). This study explored whether that is the case by considering a range of disabilities and impairments, within a small cohort.

Interviews were transcribed and then analysed with the aid of an NVivo software package (QSR NVivo 8.0 and 10.0), which provides computer-aided assistance in the identification, coding and content analysis of large tranches of qualitative data. Given the exploratory nature of the research, although a coding manual of main themes was utilised initially, an inductive approach to data analysis was taken within an intersectionality framework. Intersectionality within research involves the concurrent analyses of multiple, intersecting sources, based on the principle that any impact on one form of identity may differ depending on its combination with other potential sources of identity (Crenshaw 1991). Liasidou (2013) and Balderston (2013) advocate that it is a suitable method for interpreting experiences of disability hate crime, as it explores the way in which social and cultural categories inter-weave and compound forms of oppression and marginalisation. By considering multiple, intersecting layers of oppression or subordination, the impact of experiences of hate crime can vary. Analysis of interview data identified two interwoven trends within an intersectional framework. The first is that of intersecting hate strands. Participants recognise that hate crimes can overlap different minority strands and that individual victims are often targeted for multiple reasons. Aligned with this is the complimentary intersection of gender with disability, which was a particularly strong theme within the research findings (discussed elsewhere, in preparation). This is not unexpected, given the argument that disabled women face double disadvantage through both gender and disability, making them 
particularly vulnerable to sexual violence and exploitation (e.g. Sherry 2013b, 2010, Balderston 2013, Brownridge 2006, Brown 2004).

\section{Findings}

\section{Disabled People's Experiences of Hate Crime}

A number of findings emerged from the research interviews. This paper focuses on disabled people's interpretations of their experiences and the response to their experiences. The relationship between government policy on benefit claimants and the public categorisation of the 'deserving' or 'undeserving' victim is considered briefly for context but further detailed discussion is provided elsewhere (in preparation).

All of the research participants reported being targets of hate crime. Their stories included physical violence, verbal abuse, online abuse, harassment and sexual assaults. They report regularly experiencing abusive language and threatening behaviour in public, often in full view of passers-by or fellow customers or passengers. A number of participants describe this type of abuse as common place and repetitive, meaning they experience repeat victimisation (College of Policing 2014b, 10). Consequently, they were unlikely to report every incident to the police as there were too many in number. Aligned to this, those who did report their experiences to police told stories of inadequate or inappropriate responses from officers. Findings showed similarities to Manji's (2017) study, whose respondents doubted the police's ability to respond and saw little point in contacting authorities as a result.

This section outlines some examples of the types of experiences that participants talked about. Findings are divided by three common themes; ongoing neighbourhood disputes; stranger-perpetrators; and the lack of a 'safe space' for disabled people resulting from these experiences. Each one uses a participant story to illustrate types of 
experience and responses by the criminal justice system and begins with a description of the participant before presenting their story.

\section{Neighbourhood Battles}

Many of the participants reported that their neighbours were perpetrators of their victimisation. Typical neighbour disputes included verbal abuse, harassment and throwing objects, and are identifiable by a lengthy build up over a considerable period of time, which consequently take many years to resolve. They are often further complicated by confusion on the part of the victim as to whether they should be reporting their experiences directly to their housing officer (if in social housing) or the police. Although this is a small study in terms of participant numbers, it is arguably representative of the experiences of disability hate crime victims generally, in terms of the ongoing harassment, abuse and intimidation that is reported by other research (e.g. Macdonald, Donovan and Clayton 2017, Chakraborti, Garland and Hardy 2014a). Gemma's story below is illustrative of participants' experiences in the context of longstanding neighbourhood disputes. She reports verbal abuse, harassment and assault, demonstrating the escalation involved in much of hate crime violence that involves known perpetrators.

Gemma describes herself as 57, a single mum with a grown up son, a disability campaigner, a paranormal investigator, a photographer, gay and working class. She experienced a loss of sight following a hysterectomy and has a heart condition. She has lived in a small village in the north of England for 11 years. Gemma has had medical problems since 2004, and has fallen regularly; in the road, out of the bath, and like many other disabled people who were interviewed, had her home adjusted to suit her needs. Her heart condition means she can experience mini-strokes on a daily basis. 
Gemma's interview involved repeated abuse and harassment from local youths, as the following quotation demonstrates:

I'm standing [on the doorstep] having a fag and then like there's the same bunch of kids, kept on harassing me, they'd throw snowballs in the winter at me windows, stones at me door, like great big stones like you know, they actually made a dent in me door so bad that the housing association had to change it... erm ... they'd jump on me flat roof ... yeah? [continues] they used the bin area at the back of my property to climb on top of my roof and like they'd ring the bell, you know, and constantly ringing the bell and banging the door and... stuff like that... and I had that for two years when I was first living in this flat. Two years.

On another occasion Gemma was at her local shops, using her walking aid (a white cane) when something, possibly a water balloon, was thrown at her by a group of 'random kids'. This knocked her glasses off and hit her full in the face. As a consequence, Gemma does not use her cane any more, putting her health at greater risk if she walks unaided. She refuses to go out after dark and has someone to do her shopping for her.

Gemma repeatedly reported her experiences to the police but describes a cavalier attitude by them towards the young people who assaulted and verbally abused her. The police response was to suggest that it would "sort itself out" and saw the problem as "self-regulating". This had a deleterious effect on Gemma and impacted upon her health and emotional well-being:

I said it's not acceptable. I says, you know, they'll, they'll be banging the bloody door in and I really am not well, I said I can't be doing with any added stress from all this. 
Eventually, Gemma met her local police chief inspector at a community meeting and says she "nagged him" into a response. That encounter led to a visit from the local community police, an apology and their word that they would "keep an eye" on things. She felt that this was still not sufficient and recounts how it was not until she started regularly "haranguing the housing and the police" that she got the support she felt she deserved, which she estimated took nine years in total. Even so, there were no charges brought against the young people who verbally abused and assaulted her and her experiences have led her to restricting her lifestyle to avoid potential perpetrators. Gemma also eventually persuaded the council to install CCTV cameras for her protection.

Earlier studies have shown how this type of repeat victimisation can have longlasting and devastating effects on victims (e.g. Mikton and Shakespeare 2014, Pettitt et al. 2013, Sherry 2010, Sin et al. 2009a) and these findings provide additional weight to the literature in this area. Gemma is not a unique case but exemplifies the inadequate response by criminal justice agencies to repeated reports of incidents of disability hate crimes, particularly when it is presented or interpreted as anti-social behaviour (Macdonald, Donovan and Clayton 2017).

Many of the elements of the "Pilkington Case" are replicated in Gemma's and others interviews for this research. Fiona Pilkington took her own and her daughter's life after years of hate crime, harassment and abuse from groups of local young people that was labelled as anti-social behaviour. Following their deaths, criminal justice agencies, recognising the serious impact this case had on public confidence in the police, attempted to improve future handling of similar incidents (Giannasi 2015). It appears from Gemma's story that this has not always been successfully applied. Police protocols were established to identify and prioritise repeat callers. However, the 
participant stories presented within this research demonstrate how little has changed. As Gemma's story illustrates, it took up to nine years and 'constant' reporting for the police to respond to her seriously. In another example, participant Ruby describes repeatedly contacting her local police to report the abuse she is receiving from local youths, but their response was to encourage her not to proceed with charges.

Participants Daniel, Ruby, Hayley and Gemma recount stories of ongoing and repeated antisocial behaviour and harassment, which lead to great distress for them, and continuous contact with police or local council, who are often found lacking in an appropriate response, in echoes of the events surrounded the Pilkingtons. The evidence suggests that disabled people are continuing to be failed by a criminal justice system that is too quick to label hate incidents as anti-social behaviour and does little in response. The implications are clear; where anti-social behaviour occurs, in the form of verbal abuse or harassment, this can escalate into more serious, physical abuse and hate crimes. As Gemma's case also demonstrates, participants have had to be resilient and tenacious in repeatedly challenging the system which is failing them. This finding raises concerns for the outcomes of those disabled people do not have such levels of resilience.

\section{Random perpetrators: an everyday occurrence}

Many participants reported experiencing hate crime on a regular basis by strangers to them. This included numerous incidents of verbal abuse, harassment, threatening behaviour and physical assaults. As well as Gemma, above, this includes participants like Daniel being attacked and "beaten up"; Anne-Marie being sexually assaulted; and Amy being physically attacked in public in her wheelchair. In each case, verbal abuse was an immediate precursor to their physical assaults. The example from Grace below 
highlights how these events can occur unexpectedly, and the inappropriate police response.

Grace is a softly spoken woman in her late 50s who lives with her husband in a small seaside town in the south of England. She has an auto-immune disease that she describes as "similar to rheumatoid arthritis" but has had from birth, which led to the removal of both her hip joints and one of her elbows. Despite being able to walk when young, she is now dependent upon a wheelchair to get around.

On one occasion Grace was at her local shopping precinct. She recalls watching the ground to avoid bumps or holes that might unbalance her chair and therefore not paying particular attention to the group of young people that were coming towards her:

one of them said: 'there's another one' and then er as they got closer towards me er they all shouted 'scrounger, scum' and then as they went past one of them spat at me

Grace was alone and upset at the time but rang the police and reported the incident. They recorded her report as a disability hate crime and she recalls how the police officer treated her well and took her case seriously. Unfortunately, the investigation stalled as local CCTV was broken. As a result, the officer asked Grace if she could take a photo of her perpetrators if she saw them again; she laughs at this suggestion and adds:

I'm not sure if I'd identify them anyway because as I say I was looking at the ground and ... you know, a group of people are quite intimidating, aren't they? And males... so you know, I just kept my head down so I don't think I'd recognise them anyway 
This case highlights many participants belief that government policy changes have directly led to an increase in targeting of disabled people (Burch 2018, CRPD 2016, Garthwaite, 2015). Grace's story also emphasises the additional limitations as a result of some disabilities; being in a wheelchair meant being physically lower than other people around her and thus having less visibility. This element is echoed by another interview participant, Martin, who is also a wheelchair user:

I suppose being in a wheelchair you're at a different height so you're not walking into people and looking at them in the same size, you're sort of looking in their midriff sort of thing so you're not really seeing [them]

In addition, the cases highlight how difficult it can be to get a conviction, particularly when police resort to asking victims to take photos of their perpetrators. Police forces need to have a much greater awareness of the restrictions associated with certain types of disabilities, as well as the nuances specific to disability hate crime in particular, and as such further diversity training is required.

\section{Strangers in safe spaces}

Whether they are targeted by strangers or neighbours, the environments in which some of the victimisation occurred might have previously been expected to be safe and secure for disabled people. Many participants reported being targeted in routine locations that they frequently visit. Examples include; Ruby experiencing abuse in her doctor's surgery; Sarah reporting verbal and physical abuse at her work capability assessment; Hayley and Stuart recounting abuse in disabled parking bays. In addition, many participants also experienced abuse at home, or near their homes, including Daniel, Sarah, Ruby, Gemma and Hayley. An example of ongoing verbal abuse is described in Ruby's case, below, which demonstrates the impact of repeated incidents 
that occur in a perceived 'safe space' and the disappointing response by police officers involved.

Ruby is a married woman in her late 30 s, living in private rented accommodation above a shop in a small town in the north east of England. She has what she describes as ‘mild cerebral palsy', Asperger's Syndrome, Post Traumatic Stress Disorder (PTSD) and a brain tumour. She describes a series of abusive incidents with both known and unknown perpetrators. On one occasion Ruby was at her doctor's surgery with her husband (who is her full-time carer) when a woman sat nearby started shouting abuse at her over what Ruby can only assume was a misheard conversation. This continued outside of the surgery and the police were called. The following day Ruby encountered the same woman at the supermarket and describes how frightened she was when her abuser was "hanging on the car door, screaming abuse all the while... the detail was I'm gonna beat you up sort of thing".

Ruby's experience was clearly repeat victimisation, having involved the same perpetrator within 24 hours, and police were informed both times. On the first occasion she says the responding officer "seemed highly uninterested in it" and she was encouraged to forget about what had happened. She describes the responding officer to her second report as being more sympathetic however recounts being told:

having admitted to having memory problems the court would throw it out and so I was making a great big fuss about it

Ruby describes being given the impression that "let's not press charges if we can help it". In this way, her experiences are minimalised by the police response, and she is left feeling that she is making a big deal out of nothing. Her experiences were not unique however as many other participants spoke of similar police responses. 
Ruby's case is resonant of how disability-related abuse can occur in a perceived safe space. Her story demonstrates how individuals like Ruby can experience repeated threatening, frightening and abusive behaviour in public locations that are considered safe and are regularly visited. This may impact on disabled people's confidence such as Ruby's ability to visit her doctors' surgery and local supermarkets in future, engendering anxiety and fear about future visits (Hall and Bates 2019). Although she reports some satisfaction - and relief - with police handling of her second report, Ruby received a police response that did not take her additional needs and limitations, as a consequence of her impairments, into account. The police assumed that her memory impairment would make her a less reliable witness and Ruby reports that they told her the CPS "wouldn't touch it with a barge pole". This is in contravention of CPS guidance on hate crime which explicitly advocates that the decision as to whether or not to prosecute should be taken by the CPS and not by police.

Disability hate crime victimisation involves higher levels of threatening and intimidating behaviour and abusive language when compared to other hate strands (Macdonald, Donovan and Clayton 2017, Sherry 2010). Earlier studies reported how participants change their daily routines and avoid specific areas in order not to be attacked or to feel safe (Richardson et al. 2016, Action for Blind People 2008, DRC 2004), however, this study has highlighted how difficult it must be to feel secure in previously considered 'safe' venues.

These findings provide some support for Hollomotz's (2013) continuum of disability, oppression and violence. The concept of this non-hierarchical continuum reflects both macro-level factors, in terms of structural inequality and exclusion, and micro-level ones, such as imbalanced relationships and restricted autonomy. All of these processes are harmful and reinforcing, from verbal assault through to physical violence. 


\section{Disability hate crime within a climate of scroungers and skivers}

Exposing the social context in which disability hate crime exists was a fundamental element within this research topic. As discussed earlier, it has been suggested that welfare reforms introduced by the Government have led to disabled people being labelled benefit scroungers and frauds and an increase in the abuse of disabled people (Burch 2018, CRPD 2016, Garthwaite 2014, Briant, Watson and Philo 2011, 2013). Evidence that contextualises and contributes to the framing and understanding of welfare policy and disability in this regard is thus both timely and crucial. One of the prevailing themes from this research was the misperception and marginalisation of disabled people as fraudulent benefit claimants, and associated levels of government and media responsibility aligned to these. Participants were adamant that Government policy changes and the subsequent media hyperbole surrounding them contributed to a dramatic increase in hostility towards disabled people and this evidence is discussed in depth elsewhere (in production).

The media construction of 'fraudulent' disabled people enables members of society to justify the intrusion and challenging of perceived disabled or non-disabled people, akin to Manji’s (2017) 'conditionality’ or Garthwaite’s (2014) 'deserving' benefit recipients. Manji’s participants reported increasing stigmatisation through both disability status and benefit claiming. She argues that this has emerged through a system of 'welfare surveillance' $(2017,307)$ as a consequence of increasingly suspect attitudes towards disabled people and their entitlements to benefits. Similar evidence is also reported by Garthwaite (2014) and Baumberg, Bell and Gaffney (2012) with feelings of stigma and shame being created by media and government representations of the welfare reform process. Balderston (2013) and Burch (2018) suggest this stigma has 
in effect legitimised violence on a macro level for non-disabled people. The impact of all of this on disabled people is significant. As participant Hayley describes:

the care and compassion that used to be in this country has gone out the window. It's gone... There's all this rubbish coming out from the government, and we're paying the price, we're paying a very heavy price now.

\section{Discussion: The language of hate crime}

The language used to describe disabled people and what happens to them remains limited and stereotyped, despite an increasing interest in disability hate crimes (Quarmby 2013). Language is 'entwined' with social power, in that it not only expresses power, but is potentially also involved in challenging power (Wodak and Meyer 2009, 10). Language, and the images it conveys, can be used to justify 'unjustifiable' stereotypes and prejudices (Walters and Hoyle 2010, 235). Consequently, it can also be used to challenge stereotypes and prejudices. Unfortunately, disability hate crimes continue to be shrouded in misleading terminology. As discussed previously, ‘disablism’ often replaces ‘disability hate crime’ (Mason-Bish 2013). Harassment and assault are often referred to as 'bullying', torture as 'abuse', victims as 'vulnerable', disabled people as 'fraudsters' and hate crime as 'anti-social behaviour'. As mentioned above, 'scrounger' and 'fraud' are associated with disabled people; reflecting the power and control exerted over disabled people by dominant social and cultural discourses.

Participants' use of language emulates this in the experiences they have shared. The research participants spoke of being "vulnerable", being targeted and of the Government and media rhetoric around disability and benefits as a contributing factor to this. Similar to Garthwaite (2014, 2015), Grace's story demonstrates dominant 
narratives of media and government representations of those in receipt of welfare benefits as undeserving or fraudulent, creating fear, shame and stigma. Garthwaite's participants identified other benefit recipients as 'scroungers' and 'fakes', contributing to the ongoing deserving versus undeserving discourse. As a result, disability hate crime is on the rise. For participant Daniel it is "insipid in its ferocity"; for Gemma it "spreads like a very creeping disease". The media's use of language isolates disabled people as somehow different, as this quote by Gemma challenges;

vulnerable people, sick and disabled people, no they're PEOPLE... who happen to have impairments ... that's all.

The importance of language is also reflected in the narratives by victims themselves, as many disabled people's experiences of victimisation involve the use of derogatory and abusive language related to their impairments or conditions (as well as being labelled as frauds or scroungers). Stuart says it is the cumulative effect of language that takes its toll on him. This is as a consequence of the socially accepted use of certain terms and phrases and, to his mind, to insult or highlight the disabilities that some people have. As Burch (2018) states, disability hate speech has been normalised to the point that its harm is not recognised. However, both Gemma and Sarah challenge the stereotypes and language that disabled people are less worthy or less human by rejecting 'victim' labels (see also Ralph, Capewell and Bonnett 2016).

As suggested elsewhere, the evidence demonstrates that hate crimes are not just attacks on individuals but on the communities they represent (Perry 2001). The participants in this study spoke clearly of their experiences as being part of a collective: the majority talk of 'we' and as such, present as part of a disability community. Yet many continue to consider themselves lucky in "only" experiencing what they have, despite their continued victimisation. Comments include: 
I suppose I'm lucky that way (Martin)

we've been lucky that way... that's been it (Hayley)

compared to some people I think I've got off fairly lightly (Ruby)

but mine don't compare to what some go through (Sarah)

Stuart refers to his experiences not always being "true hate", as if what has happened to him is somehow not deserving of the hate label. In this way, victims of hate crime downplay and neutralise the significance and impact of their experiences through their own use of language, and thus are less likely to report them.

\section{Concluding thoughts}

The reasons for hate crime victimisation on individual victims are underresearched. Despite many researchers campaigning for increased research and data collection in disability hate crime, more research is still needed (Scope 2008, EHRC 2010, Emerson \& Roulstone 2014). This research addresses the deficit in knowledge about victim experiences of disability hate crimes. It highlights how disability hate crimes continue to be ignored or denied by elements of the criminal justice system and the ongoing failure to respond appropriately to reports by disabled people. As these stories demonstrate, police are failing to recognise or respond to disability hate crimes and continue to lack disability awareness. A sea change is needed to policing hate crimes that will encompass an evaluation of current policing strategies and reconfigure hate crime policing within a holistic victim framework.

This paper has demonstrated the impact of structural policy on individual experiences, resulting in an increase of hate crime victimisation on disabled people. Participants reported experiences of disability hate crimes and incidents in the form of verbal abuse, threats, intimidation, harassment, physical assaults, sexual assaults, online abuse, alleged fraud and withdrawal of services. These incidents occurred in many 
locations, both at home and in their communities, and often in perceived 'safe spaces'. Perpetrators were strangers, neighbours, local youths, co-workers, colleagues, fellow students, partners or dates, and family members, fuelled by the normalisation of hate language and reinforced by structural inequality and exclusion. The fear of potential future victimisation impacts on these participants and prohibits them from engaging with their community. Consequently, isolationist strategies contribute to the disengagement of disabled people within society and a steady withdrawal of disabled people from everyday life. Disabled people's ability to live independently, to feel safe and to provide a valuable contribution to their community is being curtailed.

References

ACPO. 2005. Hate Crime: Delivering a quality service. London: ACPO.

Action for Blind People. 2008. Report on Verbal and Physical Abuse Towards Blind and Partially Sighted People Across the UK. London: Action for Blind People. [online] [Accessed 15 February 2011] Available from: http.//www.actionforblindpeople.org.uk/abuse-survey,484,SA.html

Ahmed, S. 2001. "The Organisation of Hate." Law \& Critique 12: 345-365.

Aldridge, J. 2014. "Working with vulnerable groups in social research: dilemmas by default and design." Qualitative Research 14(1): 112-130.

BBC News Online. 2011. Benefit applicants - '75\% fit to work or drop claims'. BBC News 28 April 2011. [online] [Accessed 17 September 2016] Available from: http://www.bbc.co.uk/news/uk-politics-13217824

Balderston, S. 2013. "Victimized again? Intersectionality and injustice in disabled women's lives after hate crime and rape." In Gendered Perspectives on Conflict and Violence: Part A (Advances in Gender Research, Volume 18A) edited by M. Texler Segal and V. Demos, 17 - 51. Emerald Group. 
Barr, B., D. Taylor-Robinson, D. Stuckler, R. Loopstra, A. Reeves and M. Whitehead. 2016. “"First, do no harm': are disability assessments associated with adverse trends in mental health? A longitudinal ecological study." Journal of Epidemiology \& Community Health 70: 339-345.

Barton, L. ed. 1996. Disability \& Society: Emerging Issues and Insights. Harlow: Pearson Education.

Berzins, K., A. Petch, and J. M. Atkinson. 2003. "Prevalence and experience of harassment of people with mental health problems living in the community." British Journal of Psychiatry 183 (12): 526-533.

Blee, K. M. 2007. "The Microdynamics of Hate Violence: Interpretive Analysis and Implications for Responses.” American Behavioral Scientist 51 (2): 258-270.

Bowling, B. 1998. Violent Racism Victimization, policing and social context. Oxford: Clarenden Press.

Briant, E., N. Watson, and G. Philo. 2011. Bad News for Disabled People: How the Newspapers are Reporting Disability. Project Report. Strathclyde Centre for Disability Research and Glasgow Media Unit: University of Glasgow.

Briant, E., N. Watson, and G. Philo. 2013. "Reporting disability in the age of austerity: the changing face of media representation of disability and disabled people in the United Kingdom and the creation of new 'folk devils'." Disability \& Society 28(6): 874-889.

Brown, H. 2004. “A Rights-Based Approach to Abuse of Women with Learning Disabilities." Tizard Learning Disability Review 9(4): 41-44.

Brownridge, D. A. 2006. "Partner Violence Against Women With Disabilities: Prevalence, Risk, and Explanations.” Violence Against Women 12(9): 805-822.

Burch, L. 2018. “'You are a parasite on the productive classes': online disablist hate speech in austere times." Disabilith \& Society 33(3): 392-415.

Chakraborti, N. 2015. "Framing the boundaries of hate crime." In The Routledge International Handbook on Hate Crime, edited by N. Hall, A. Corb, P. Giannasi, \& J.G.D. Grieve, 13-23. Oxon: Routledge.

Chakraborti, N., and J. Garland. 2009. Hate Crime: Impact, Causes, Consequences. London: Sage.

Chakraborti, N., J. Garland, and S.-J. Hardy. 2014a. The Leicester Hate Crime Project: Findings and Conclusions. University of Leicester. [online] [Accessed 18 August 
2016] Available from:

https://www2.le.ac.uk/departments/criminology/hate/documents/fc-full-report

Chakraborti, N., J. Garland, and S.-J. Hardy. 2014b. The Leicester Hate Crime Project:

Briefing Paper 1: Disablist Hate Crime: Victims' Perspectives. University of

Leicester. [online] [Accessed 18 August 2016] Available from:

https://www2.le.ac.uk/departments/criminology/hate/documents/bp1-disablist-hatecrime/view

Cole, E. R. 2009. "Intersectionality and Research in Psychology.” American

Psychologist 64(3): 170-180.

College of Policing 2014a. National Policing Hate Crime Strategy 2014. Coventry:

College of Policing.

College of Policing 2014b. Hate Crime Operational Guidance 2014. Coventry: College of Policing.

Committee on the Rights of Persons with Disabilities. 2016. Inquiry concerning the United Kingdom of Great Britain and Northern Ireland Carried out by the Committee under Article 6 of the Optional Protocol to the Convention. Geneva: UN Committee on the Rights of Persons with Disabilities.

Cook, T., and P. Inglis. 2012. "Participatory research with men with learning disability: informed consent." Tizard Learning Disability Review 17(1): 92-101.

Corcoran, H., and K. Smith. 13 October 2016. Hate Crime, England and Wales, 2015/16. Statistical Bulletin 11/16. London; Home Office. Crown Copyright. [online] [Accessed 21 October 2016] Available from: https://www.gov.uk/government/uploads/system/uploads/attachment_data/file/5 59319/hate-crime-1516-hosb1116.pdf

Crenshaw, K. W. 1991.”Mapping the Margins: Intersectionality, Identity Politics, and Violence Against Women of Color.” Stanford Law Review 43(6): 1241-99.

Crown Prosecution Service (CPS) 2010b. Guidance on the distinction between vulnerability and hostility in the context of crimes committed against disabled people. 17 March 2010. [online] [Accessed January 2012] Available from: http://www.cps.gov.uk/legal/d_to_g/disability_hate_crime_/\#content

Department for Work and Pensions (DWP) 2012. Disabled People's User-Led Organisations: Making a Difference: Disability Hate Crime. London: Crown Copyright/ODI. Published December 2012. 
Disability Rights Commission \& Capability Scotland (DRC) 2004. Hate Crime against Disabled People in Scotland: A survey report. Manchester: Disability Rights Commission and Edinburgh: Capability Scotland.

Dupont, I. 2008. "Beyond Doing No Harm: A Call for Participatory Action Research with Marginalized Populations in Criminological Research.” Critical Criminology 16: 197-207.

Emerson, E., and A. Roulstone. 2014 "Developing an Evidence Base for Violent and Disablist Hate Crime in Britain: Findings from the Life Opportunities Survey." Journal of Interpersonal Violence. [online] Published online 28/05/2014 [Accessed 17 October 2014] Available from: http://jiv.sagepub.com/content/29/17/3086

Equalities and Human Rights Commission. 2010. How fair is Britain? Equality, Human Rights and Good Relations in 2010. The First Triennial Review. London: EHRC.

Equalities and Human Rights Commission. 2011. Hidden in Plain Sight: Inquiry into Disability Related Harassment. Final Report. London: EHRC.

Esin, C. 2011. "Narrative Analysis Approaches.” In Qualitative Research Methods in Psychology: Combining Core Approaches, edited by N. Frost, 92-117. Berkshire: OUP

Garland, J. 2011. "Difficulties in defining hate crime victimization.” International Review of Victimology. Published online 9 November 2011. [online] [Accessed 14 November 2011] Available from: http://irv.sagepub.com/content/early/2011/09/23/0269758011422473

Garthwaite, K. 2011. “The language of shirkers and scroungers?' Talking about illness, disability and coalition welfare reform." Disability \& Society 26(3): 369-372.

Garthwaite, K. 2014. “"Fear of the brown envelope: exploring welfare reform with longterm sickness benefits recipients." Social Policy and Administration 48(7): 782798.

Garthwaite, K. 2015. “'Keeping meself to meself” How social networks can influence narratives of stigma and identity for long-term sickness benefit recipients." Social Policy and Administration 49(2): 199-212.

Giannasi, P. 2015. "Policing and Hate Crime". In Responding to Hate Crime: The Case for Connecting Policy and Research, edited by N. Chakraborti and J. Garland, 331-342. Bristol: Policy Press. 
Gillen, S. 2007. “Targets of Hate Crime.” Community Care, 1692: 28-29.

Greater London Action on Disability (GLAD) 2004. Disabled people and the police - a new relationship. Report from the December 2004 Community Engagement Committee. London: Metropolitan Police Authority pp 41, RP78260. [online] [Accessed 9 October 2014] Available from: http://democraticservices.hounslow.gov.uk/(S(okikb345hj0x4vzpvupsly45))/mg Convert2PDF.aspx $?$ ID $=13073$

Greenhalgh, C., and E. Gore. 2009. Disability Review 2009. Leonard Cheshire Disability. [online] [Accessed 12 January 2012] Available from: http://www.lcdisability.org/?lid=11009

HM Government. 2009. Hate Crime: The Cross-Government Action Plan. London: Crown Copyright

HM Government. 2010. Equality Act 2010. London: OPSI

HM Government. 2012. Challenge it, Report it, Stop it: The Government's Plan to Tackle Hate Crime. March 2012. London: OPSI

Hall, E., and E. Bates. 2019. "Hatescape? A relational geography of disability hate crime, exclusion and belonging in the city." Geoforum101: 100-110. doi: 10.1016/j.geoforum.2019.02.024

Hall, N. 2005. Hate Crime. Cullompton: Willan Publishing Hall, N. 2013. Hate Crime. $2^{\text {nd }}$ ed. Oxon: Routledge Hollomotz, A. 2013. "Disability and the continuum of violence." In Disability, Hate Crime and Violence, edited by A. Roulstone \& H. Mason-Bish, 52-63. London: Routledge.

Home Office. 2016. Action Against Hate: The UK Government's plan for tacking hate crime. July 2016. [online] [Accessed 20 September 2016] Available from: http://www.report-it.org.uk/files/action_against_hate__uk_government_s_plan_to_tackle_hate_crime_2016.pdf

Hughes, K., M. A. Bellis, L. Jones, S. Wood, G. Bates, L. Eckley, E. McCoy, C. Mikton, T. Shakespeare, and A. Officer. 2012. "Prevalence and risk of violence against adults with disabilities: A systematic review and meta-analysis of observational studies." The Lancet 379(9826): 1621-16.

Iganski, P., and A. Sweiry. 2016. "How 'Hate' Hurts Globally”. In The Globalization of Hate, edited by J. Schweppe and M.A. Walters, 96-107. Oxford: OUP. 
Jacobs, J. B., and K. Potter. 1998. Hate Crimes: Criminal Law \& Identity Politics. New York: OUP.

Jenness, V., and K. Broad. 1997. Hate Crimes: New Social Movements and the Politics of Violence. New York: Aldine de Gruyter.

Landman, R. A. 2014. ““A counterfeit friendship': Mate Crime and people with learning disabilities." Journal of Adult Protection 16(6): 355-366.

Lawrence, E. 5 May 2011. 'Evidence' suggests benefit fraud but injustice for disabled people is more apt. TheGuardian.com [online] [Accessed 25 July 2016] Available from: https://www.theguardian.com/society/2011/may/05/disabled-benefitfraud-injustice-edward-lawrence

Levin, J. 2013. “Disablist violence in the US: Unacknowledged hate crime.” In Disability, Hate Crime and Violence, edited by A. Roulstone and H. MasonBish, 95-105. London: Routledge.

Liasidou, A. 2013. "Intersectional understandings of disability and implications for a social justice reform agenda in education policy and practice." Disability \& Society 28(3): 299-321.

Macdonald, S., C. Donovan, and J. Clayton. 2017. "The disability bias: understanding the context of hate in comparison with other minority populations." Disability and Society 12(4): 483-499.

Macpherson, W. Sir. 1999. Stephen Lawrence Inquiry: Report of an inquiry by Sir William Macpherson of Cluny. London: HMSO.

Manji, K. 2017. "Social Security Reform and the Surveillance State: Exploring the Operation of 'Hidden Conditionality' in the Reform of Disability Benefits Since 2010." Social Policy \& Society 16(2): 305-314.

Marsh, S. 2011. A hatred bred from the top. The Guardian. 16/09/2011.

Mason, G. 2005. "Hate Crime and the Image of the Stranger." British Journal of Criminology 45 (6): 837-859.

Mason, G. 2014. "The symbolic purpose of hate crime law: Ideal victims and emotion." Theoretical Criminology 18(1): 75-92.

Mason, G., J. McCulloch, and J. Maher. 2015. "Policing Hate Crime: Markers for Negotiating Common Ground in Policy Implementation.” Policing and Society 26(6): 680-697. 
Mason-Bish, H. 2013. "Conceptual issues in the construction of disability hate crime." In Disability, Hate Crime and Violence, edited by A. Roulstone and H. MasonBish, 11-24. London: Routledge.

Mikton, C., and T. Shakespeare. 2014. "Introduction to Special Issue on Violence Against People With Disability.” Journal of Interpersonal Violence 29(17): 3055-3062.

NACRO. 2002. Access all areas: A guide for community safety partnerships on working more effectively with disabled people. London: NACRO

National Schizophrenia Fellowship Scotland (NSF) 2001. Give us a break: Exploring harassment of people with mental health problems. Edinburgh: NSF Scotland.

Nind, M. 2017. “The practical wisdom of inclusive research.” Qualitative Research 17(3): 278-288.

Northern Ireland Statistics and Research Agency (NISRA) 2007. The Prevalence of Disability and Activity Limitations amongst adults and children living in private households in Northern Ireland. Bulletin 1 July 2007. Final Report from the Northern Ireland Survey of people with Activity Limitations and Disabilities. Belfast: NISRA.

Office for Disability Issues (ODI) 2011. Life Opportunities Survey. Wave one results, 2009/11. London: ODI/HM Govt.

Office for Disability Issues (ODI) 2014. Disability Facts and Figures. 16 January 2014. [online] [Accessed 24 September 2016] Available from: https://www.gov.uk/government/publications/disability-facts-andfigures/disability-facts-and-figures

Oliver, M. 1990. The Politics of Disablement. Basingstoke: Macmillan.

Perry, B. 2001. In the name of Hate: Understanding Hate Crime. New York/London: Routledge.

Perry, B. 2003. "Where do we go from here? Researching hate crime." Internet Journal of Criminology. [Online] [Accessed 9 March 2010]. Available from: http://www.internetjournalofcriminology.com/Where\%20Do\%20We\%20Go\%2 0From\%20Here.\%20Researching\%20Hate\%20Crime.pdf

Perry, B. 2015. "Exploring the community impacts of hate crime." In The Routledge International Handbook on Hate Crime, edited by N. Hall, A. Corb, P. Giannasi, and J.G.D. Grieve, 47-58. Oxon: Routledge.

Perry, J. 2004. “Is justice taking a beating?” Community Care 1 April 2004: 44-45. 
Petersilia, J. R. 2001. "Crime Victims with Developmental Disabilities: A Review Essay." Criminal Justice and Behavior 28(6): 655-694.

Pettitt, B., S. Greenhead, H. Khalifeh, V. Drennan, T. Hart, J. Hogg, R. Borschmann, E. Mamo, and P. Moran. 2013. At risk, yet dismissed: The criminal victimisation of people with mental health problems. London: Victim Support \& Mind.

Piggott, L. 2011. “Prosecuting Disability Hate Crime: a disabling solution?” People, Place \& Policy Online 5(1): 25-34.

Prime Minister's Strategy Unit. 2005. Improving the life chances of disabled people. London: Cabinet Office.

Quarmby, K. 2008. Getting Away with Murder: Disabled People's experiences of hate crime in the UK. London: Scope, Disability Now and UKDPC.

Quarmby, K. 2013. "Media reporting and disability hate crime." In Disability, Hate Crime and Violence, edited by A. Roulstone \& H. Mason-Bish, 64-79. London: Routledge.

Quarmby, K. 2015. Disability hate crime motivation survey - results. July 2015. [online] [Accessed 13 September 2016] Available from: https://katharinequarmby.wordpress.com/2015/07/

Ralph, S., C. Capewell and E. Bonnett. 2016. "Disability hate crime: persecuted for difference." British Journal of Special Education/ NASEN 43(3): 215-232.

Richardson, K., J. Beadle-Brown, J. Bradshaw, C. Guest, A. Malovic, and J. Himmerich. 2016. ““I felt that I deserved it” - experiences and implications of disability hate crime." Tizard Learning Disability Review 21(2): 80-88.

Riley-Smith, B. 2012. Disability hate crime: is 'benefit scrounger' abuse to blame. The Guardian Online 14.08.2012 [online] [Accessed 17 September 2016] Available from: https://www.theguardian.com/society/2012/aug/14/disability-hate-crimebenefit-scrounger-abuse

Scope. 2008. Disability hate crime fuelled by 'casual and institutional disablism'. [online] [Accessed 13 March 2009] Available from: http://www.scope.org.uk/news/disability-hate-crime-fuelled\%E2\%80\%9Ccasual-and-institutional-disablism\%E2\%80\%9D

Scope. 2011. Deteriorating attitudes towards disabled people. [online] [Accessed 19 May 2011] Available from: http://www.scope.org.uk/news/attitudes-towardsdisabled-people-survey 
Shapland, J., and M. Hall. 2007. "What do we know about the effects of crime on victims?" International Review of Victimology 14(2): 175-217.

Sherry, M. 2010. Disability hate crimes: does anyone really hate disabled people? Burlington: Ashgate.

Sherry, M. 2013a. "International perspectives on disability hate crime.” In Disability, Hate Crime and Violence, edited by A. Roulstone and H. Mason-Bish, 80-91. London: Routledge.

Sherry, M. 2013b. "Feminist reflections on disability hate crime. Gendered Perspectives on Conflict and Violence, Part A." Advances in Gender Research 18(A): 53-66.

Sin, C. H. 2013. "Making disablist hate crime visible: Addressing the challenges of improving reporting". In Disability, Hate Crime and Violence, edited by A. Roulstone and H. Mason-Bish, 147-165. London: Routledge.

Sin, C. H. 2015. "Hate crime against people with disabilities.” In The Routledge International Handbook on Hate Crime, edited by N. Hall, A. Corb, P. Giannasi and J.G.D. Grieve, 193-206. Oxon: Routledge.

Sin, C.H. 2016. "Commentary on "'I felt I deserved it' - experiences and implications of disability hate crime." Tizard Learning Disability Review 21(2): 89-94

Sin, C H., A. Hedges, C. Cook, N. Mguni, and N. Comber. 2009a. Disabled people's experiences of targeted violence and hostility. EHRC Research Report 21. EHRC \& Office for Public Management.

Sin, C. H., N. Mguni, C. Cook, N. Comber, and A. Hedges. 2009b. "Disabled victims of targeted violence, harassment and abuse: barriers to reporting and seeking redress." Safer Communities 8(4): 27-34.

Sobsey, D. 1994. Violence and abuse in the lives of people with disabilities: The end of silent acceptance? Baltimore: Brooks

Thiara, R. K. and G. Hague. 2013. "Disabled women and domestic violence: Increased risk but fewer services." In Disability, Hate Crime and Violence, edited by A. Roulstone and H. Mason-Bish, 106-117. London: Routledge.

Thomas, P. 2011. “'Mate crime': ridicule, hostility and targeted attacks against disabled people.” Disability \& Society 26(1): 107-111.

Thomas, P. 2013. "Hate crime or mate crime: Disablist hostility, contempt and ridicule." In Disability, Hate Crime and Violence, edited by A. Roulstone and H. Mason-Bish, 135-146. London: Routledge 
Van Dijk, J. 2009. "Free the victim: A critique of the Western conception of victimhood". International Review of Victimology 16(1): 1-33.

Vincent, F., K. Radford, N. Jarman, A. Martynowicz and M.-K. Rallings. 2009. Hate Crime against People with Disabilities: A baseline study of experiences in Northern Ireland [online] [Accessed 1 April 2011] Available from: http://www.ofmdfmni.gov.uk/hate_crime_against_people_with_disabilities_pd f $760 \mathrm{~kb} . p d f$

Void, J. 17/09/2013. The latest benefit fraud crackdown is a grim sign of the times. Theguardian.com [online] [Accessed 13 September 2016] Available from: https://www.theguardian.com/commentisfree/2013/sep/17/benefit-fraudcrackdown-grim-sign-times

Walker, P. 04/11/2009. Charity says 9\% of disabled people have been victims of hate crime. The Guardian, p12.

Walters, M. and C. Hoyle. 2010. "Healing Harms and Engendering Tolerance: the Promise of Restorative Justice for Hate Crime." In Hate Crime: Concepts, Policy, Future Directions, edited by N. Chakraborti, 228-248. Cullompton: Willan.

Walters, M., S. Wiedlitzka and A. Owusu-Bempah. 2017. Hate Crime and the Legal Process: Options for Law Reform. Final Report October 2017. Sussex: University of Sussex.

Williams, M. L. and J. Tregidga. 2014. "Hate Crime Victimization in Wales: Psychological and Physical Impacts Across Seven Hate Crime Victim Types.” British Journal of Criminology 54(5): 946-967.

Wodak, R. \& M. Meyer. 2009. “Critical Discourse Analysis: History, Agenda, Theory, and Methodology." In Methods of Critical Discourse Analysis, edited by R. Wodak and M. Meyer. 2nd ed. London: Sage.

Wood, J. and K. Edwards. 2005. "Victimization of mentally ill patients living in the community: is it a life-style issue?" Legal and Criminological Psychology 10: 279-290.

World Health Organization (WHO) (2011) World Report on Disability. Geneva: WHO 